\title{
The development and challenges of draw solutions for forward osmosis
}

\section{processes}

\author{
Xie Kang ${ }^{1, a}$, Song Jing ${ }^{2, b}$, Qiu Liping ${ }^{1, c}$, Wang Jiabin ${ }^{1, d}$, Zhang Shoubin ${ }^{1, e}$ Kang \\ Xingsheng $^{3, f}$ and Zhang Liqing ${ }^{1, g}$ \\ ${ }^{1}$ School of Civil Engineering and Architecture, University of Jinan, Jinan, Shandong 250022, China \\ ${ }^{2}$ Shandong Province Environmental Protection Technology Service Center, Jinan, Shandong \\ 250102, China \\ ${ }^{3}$ Shandong Academy of Environmental Science, Jinan, Shandong 250013, China

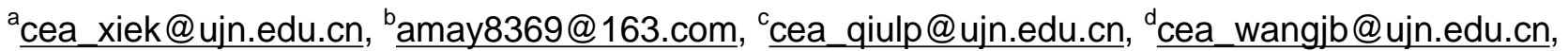

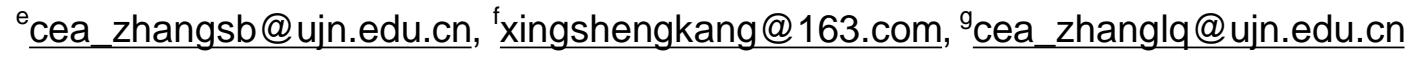

Keywords: forward osmosis, draw solutions, commercially available compounds, Synthetic materials

\begin{abstract}
The development of draw solution is of great importance to the industrial application of forward osmosis technology. At present, the draw solutions are defined as two main types. In this study, we summarized the common draw solutions used in FO process after 2000, and detailed the two types draw solutions, responding to commercially available compounds (including volatile compounds, nutrient compounds, inorganic salts and organic salts) and synthetic materials.
\end{abstract}

\section{Introduction}

Forward osmosis (FO) which is known as osmosis, is a widespread physical phenomenon. It is an osmotically driven membrane separation process without additional pressure [1]. In 1748, French scientist Nollet discovered the phenomenon of osmosis, marking the beginning of the application of forward osmosis technology. Because the forward osmosis process is spontaneous process, it has the advantages of equipment simple, operation easy, energy saving and environmental protection. Since 1860s, reverse osmosis technology has undergone a long time of development, from membrane materials, engineering technology, market development, and eventually become one of the most successful membrane technology. Compared to reverse osmosis, the forward osmosis process application is still in the initial stage of development[2].

Forward osmosis has the advantages of low energy consumption, low pollution, high recovery and so on. Its application range is very extensive, involving industrial production and all aspects of daily life. Forward osmosis technology in seawater desalination, power generation, industrial wastewater treatment, food industry, aerospace industry and the pharmaceutical industry has achieved a certain degree of development[3]. It also has advantages in avellating fouling and low energy consumption, which integration with other technologies can form process of technological innovation. 
The realization of forward osmosis requires two critical conditions: high osmotic pressure draw solution and selective permeable membrane. The ideal draw solute should have the following characteristics: 1) high solubility in water, or small molecular weight, in order to produce a higher osmotic pressure; 2) non-toxic, stable and secure in the water; 3) and forward osmosis membrane chemical compatibility, no chemical reaction with membrane, and membrane will not be degradation; 4) can conveniently and economically separated and reused.

In this study, the draw solution development status and trends are summarized in order to get more attention. It is promoted the rapid development of forward osmosis technology, to solve the problem of shortage of water resources in the world[4].

\section{Draw solution of forward osmosis}

Due to the need of forward osmosis technology, the draw solution shows a variety of development in recent decades. Many water soluble and high permeable media are being developed as solutes in the draw solution after 2000, as shown in table 1.

Table 1 Overview of the development and recovery approaches of draw solutes used in FO technology after 2000

\begin{tabular}{|c|c|c|c|c|}
\hline Year & Researcher(s) & Draw solute(s) & Method of recovery & Drawbacks \\
\hline & & & $\mathrm{SO} 2$ & \\
\hline 2002 & McGinnis & $\mathrm{KNO}_{3} \& \mathrm{SO}_{2}$ & $\begin{array}{l}\text { wasrecycledthrough } \\
\text { standard means }\end{array}$ & Energy intensive, toxic \\
\hline 2005-2007 & McCutcheon et a & $\begin{array}{c}\mathrm{NH}_{3} \& \mathrm{CO}_{2}\left(\mathrm{NH}_{4} \mathrm{HCO}_{3}\right) \text { or } \\
\mathrm{NH}_{4} \mathrm{OH}-\mathrm{NH}_{4} \mathrm{HCO}_{3}\end{array}$ & $\begin{array}{c}\text { Moderate } \\
\text { heating }\left(\sim 60{ }^{\circ} \mathrm{C}\right)\end{array}$ & $\begin{array}{l}\text { High reverse draw solute flux } \\
\text { Insufficient removal of } \\
\text { ammonia }\end{array}$ \\
\hline 2007 & Adham et al & Magnetic nanoparticles & $\begin{array}{c}\text { Captured by a canister } \\
\text { separator }\end{array}$ & $\begin{array}{l}\text { Poor performance, } \\
\text { agglomeration }\end{array}$ \\
\hline 2007 & Adham et al & Dendrimers & Adjusting $\mathrm{pH}$ or UF & Not feasible \\
\hline 2007 & Adham et al & Albumin & $\begin{array}{c}\text { Denatured and } \\
\text { solidified by heating }\end{array}$ & Not feasible \\
\hline 2008 & McCormick et al. & Salt, ethanol & $\begin{array}{l}\text { Pervaporation-based } \\
\text { separations }\end{array}$ & $\begin{array}{l}\text { High reverse draw solute flux } \\
\text { and low water flux }\end{array}$ \\
\hline 2010 & Yen et al. & 2-Methylimidazole based solutes & $\begin{array}{l}\text { Membrane Distillation } \\
\text { (MD) }\end{array}$ & Materials costly \\
\hline $2010-2011$ & Ling et al Ge et al. & Magnetic nanoparticles & $\begin{array}{l}\text { Recycled by external } \\
\text { magnetic field }\end{array}$ & Agglomeration \\
\hline 2011 & Li et al. & $\begin{array}{l}\text { Stimuli-responsive polymer } \\
\text { hydrogels }\end{array}$ & $\begin{array}{l}\text { Deswelling of the } \\
\text { polymer hydrogels }\end{array}$ & $\begin{array}{l}\text { Energy intensive, Poor water } \\
\text { flux }\end{array}$ \\
\hline 2011 & Ling \& Chung & Hydrophilic nanoparticles & $\mathrm{UF}$ & Poor water flux \\
\hline 2011 & Phuntsho et al. & Fertilizers & None & Only applicable in agriculture \\
\hline 2011 & Iyer and Linda & fatty acid-polyethylene glycol & Thermal method & Poor water flux \\
\hline 2012 & Su et al. & Sucrose & NF & Relatively low water flux \\
\hline 2012 & Ge et al. & Polyelectrolytes & UF & Relatively high viscosity \\
\hline 2012 & Noh et al. & $\begin{array}{l}\text { Thermo-sensitive solute } \\
\text { (Derivatives of Acyl- TAEA) }\end{array}$ & Not studied & Poor water flux \\
\hline 2012 & Yong et al. & urea, ethylene glycol, and glucose & Not studied & Low water flux and high \\
\hline
\end{tabular}




\begin{tabular}{ccccc}
\hline Year & Researcher(s) & Draw solute(s) & Method of recovery & Drawbacks \\
\hline 2012 & Bowden et al. & Organic salts & Ro solute flux \\
2012 & Carmignani et al & polyglycol copolymers & NF & Low water flux, energy \\
2012 & Stone et al. & hexavalent phosphazene salts & Not studied & Not economical and practical
\end{tabular}

As can be seen from Table 1, in order to find more suitable draw solutes, the researchers tested a variety of compounds as draw solutes. Generally, the draw solutes can be divided into two categories, i.e. commercially available compounds and synthetic compounds. The evolution of these two categories of compounds is given below.

\section{commercially available compounds}

Volatile compounds. The common volatile draw solutes are ammonium bicarbonate, sulfur dioxide, potassium nitrate and so on. These compounds can be separated from product water by heating, cooling or distillation. The volatile gases can be dissolved back into water to regenerate the draw solutions[5].

Nutrient compounds. The common Nutrient compounds are Glucose, Sucrose e.g. it also shows a higher osmotic pressure and no need to regenerate.

Inorganic salts. Through the screened process, about 14 inorganic salts remained in more than 500 compounds in initial. It is always evaluated the water flux and reverse salt flux of selected salts. The $\mathrm{MgSO}_{4}, \mathrm{KHCO}_{3}, \mathrm{NaHCO}_{3}, \mathrm{Na}_{2} \mathrm{SO}_{4},\left(\mathrm{NH}_{4}\right)_{2} \mathrm{SO}_{4}$, and $\mathrm{K}_{2} \mathrm{SO}_{4}$ are considered suitable draw solutions which can show lower reverse salt flux because of their larger hydrated anions.

Organic salts. The organic salts are defined as the combination of an organic anion with an organic or inorganic cation. The research conclusions show that the shorter carbon chain always exhibit a better performance than longer carbon chain for the same cation species of organic salts.

\section{Synthetic materials}

Hydrophilic magnetic nanoparticles (MNPs) and polymer hydrogels are the main synthetic materials as draw solutes [6]. These synthetic materials have been applied to FO processes and exhibit great potentials as draw solutes. They are considered as promising draw solutes in FO processes. It was observed that these synthetic materials showed a higher osmotic pressure and easy to regenerate with energy saving. But the usage of these synthetic materials still in lab-scale stage. It is still a long way to employing these synthetic materials in large-scale stage. Just like the operation parameters, optimal recovery means and potential threat of purified water still need further study.

\section{conclusion}

As for the draw solutes in forward osmosis, it is a challenge to develop a more suitable and efficient draw solute to promote the development and maturation of the forward osmosis technology. In order to become a mature technology, forward osmosis technology needs to make innovative research on the draw solutes, and it also needs low cost and recycling draw solutes. At present, commercial membrane material is only cellulose acetate membrane developed by HTI company. It can be seen that forward osmosis technology is still in its infancy, and its development of space is 
huge. Forward osmosis technology will become one of the key technologies to solve the problems of water resources and energy shortage which hinder the sustainable development of human beings.

\section{Acknowledgements}

This work was financially supported by the research foundation of University of Jinan (XKY1618), Science and technology plan project of Shandong higher education institutions (J17KA198), National Natural Science Foundation of China (51678726, 51278225, 51408260), Science and Technology Development Projects of Shandong Province (2016GGB01157), Shandong Provincial Natural Science Foundation (ZR2013EEQ007, ZR2015EM021).

\section{References}

[1] T.S.Chung, X.Li, R.C.Ong, Q.Ge, H.L.Wang, G.Han: Curr. Opinion Chem. Eng., Vol.1(2012), p. 24

[2] M. Elimelech, W.A. Phillip: Science, Vol.333(2011), p.712

[3] A. Subramani, M. Badruzzaman, J. Oppenheimer, J.G. Jacangelo: Water Res., Vol.45(2011), p.1907

[4] L.F. Greenlee, D.F.Lawler, B.D. Freeman, B. Marrot, P. Moulin, :Water Res., Vol.43 (2009), p. 2317

[5] E.M. Garcia-Castello, J.R. McCutcheon, M. Elimelech: J.Membr.Sci. Vol. 338(2009), p. 61-66.

[6] J.R. McCutcheon, R.L. McGinnis, M. Elimelech: Desalination, Vol.174(2005), p.1 